\title{
Control of avoidance by a discriminative stimulus
}

\author{
STEPHAN G. LYNN' and JOHN A. NEVIN, ${ }^{2}$ Swarthmore \\ College, Swarthmore, $\mathrm{Pa} .19081$
}

Four rats were exposed to an avoidance procedure in which shocks were scheduled at $10 \mathrm{sec}$ intervals and light and darkness alternated every 2 min. In light $\left(S^{D}\right)$, a response prevented all shocks programmed for that $S^{D}$ period; shocks were unavoidable in $S \triangle$. Response latencies and distribution in $S^{D}$ and $S \triangle$ indicated that the contingencies had established discriminative control of responding. Differential responding was eliminated during extinction.

Avoidance behavior has been interpreted almost exclusively in terms of two-factor theory since the work of Mowrer \& Lamoreaux (1942). Recently the validity of this interpretation has been challenged by Herrnstein \& Hineline (1966) and Herrnstein (1968). Herrnstein contends that avoidance behavior can be explained by the contingency between the response and the reduction of shock frequency. The mediating fear response is dismissed as an unnecessary and complicating theoretical construct in a system in which the observable reduction of shock density is alone sufficient as the reinforcer of behavior. The CS in the conventional avoidance experiment is then viewed as a discriminative stimulus. The following experiment, based on a paradigm proposed by Herrnstein (1968), provides an application of this theoretical interpretation. It is designed as an operant discrimination $\left(\mathrm{S}^{\mathrm{D}}\right)$ procedure in which alternative stimulus conditions define different response contingencies, with the avoidance of programmed shocks and consequent reduction of shock frequency acting as the reinforcing consequence.

Subjects

The Ss were four male Swarthmore strain rats, approximately 100 days old, with continuous access to food and water in the home cages.

Apparatus

The experiment was conducted in a Grason-Stadler E3125B chamber with a Plexiglas bar mounted $3.3 \mathrm{~cm}$ above the level of the shock grid, and protruding $3.3 \mathrm{~cm}$ into the chamber. A force of $6.2 \mathrm{~g}$ was required to operate its switch. The experiment was programmed and the data recorded automatically. Shocks of $0.3 \mathrm{sec}$ and $0.5 \mathrm{~mA}$ were administered by a Grason-Stadler E1064S shock source. The discriminative stimulus consisted of the onset of the houselight and two pilot lights in an otherwise dark chamber.

Procedure

Training--The bar-press training procedure consisted of continuous shock interrupted by a $10-\mathrm{sec}$ nonshock period contingent upon response. Shock was reinstated $10 \mathrm{sec}$ after the last response had occurred. The procedure was designed to initiate bar-pressing rapidly.

FI(FI)-Shocks were programmed at fixed $10 \mathrm{sec}$ intervals and light $\left(\mathrm{S}^{\mathrm{D}}\right)$ and darkness $\left(\mathrm{S}^{\Delta}\right)$ alternated every 2 mii throughout the session. The presence of $S^{D}$ defined a period during which a single response prevented the occurrence of all shocks programmed from the moment of response until the cessation of the $\mathrm{S}^{\mathrm{D}}$ period. There was no contingency in the $S^{\Delta}$ (dark) period; shocks were presented every $10 \mathrm{sec}$ and the response had no effect.

FI(VI) and VI(VI)-The fixed temporal intervals involved in the initial procedure were altered in later sessions. In a procedure called FI(VI), the light onset or offset was programmed at regular 2-min intervals, but the shocks within these periods were sclieduled to occur every $10 \mathrm{sec}$ on the average with no shock-shock interval less than 5 sec. In the
VI(VI) schedule both temporal features of the procedure became variable. $S^{D}$ and $S^{\Delta}$ alternated irregularly at variable intervals averaging $2 \mathrm{~min}$ (with no period less than $30 \mathrm{sec}$ nor more than $210 \mathrm{sec}$ ). Shocks were scheduled as in FI(VI).

Extinction-Stimuli and shocks were scheduled as in VI(VI) but responses had no effect upon the shocks received. Note that this procedure differs from the conventional avoidance extinction in that shock was continued and only the contingency eliminated.

Each daily session was $2 \mathrm{~h}$ long including any training time which may have been programmed. The total number of shocks received and responses emitted during $S^{D}$ and $S^{\Delta}$ were recorded for each 2-h session. During Fl(FI) and FI(VI), responses were also counted every $10 \mathrm{sec}$ throughout $\mathrm{S}^{\mathrm{D}}$ and $S^{\Delta}$. The time between the stimulus change and the first response thereafter was recorded on cumulative running time meters; thus, the total latency in $S^{D}$ or $S^{\Delta}$ represents the cumulative sum of all individual latencies occurring during the $30 \mathrm{~S}^{\mathrm{D}}$ or $\mathrm{S}^{\Delta}$ periods within a 2 -h session.

Only one response per $S^{D}-S^{\Delta}$ cycle, at the onset of $S^{D}$, was necessary to achieve maximal avoidance; all other responses were superfluous. The only immediately relevant feature of the response was its temporal relationship to the changing stimulus conditions and consequently to the contingencies therein defined. Therefore, response latencies and the distribution of responses within the $\mathrm{S}^{\mathrm{D}} \cdot \mathrm{S}^{\Delta}$ cycle were the major dependent variables.

Rat No. 5 received $40 \mathrm{~min}$ of the bar-press training procedure distributed over the initial periods of the first six days of the experiment with a final training period of $60 \mathrm{~min}$ at the start of the seventh day of training. It continued to the FI(FI), FI(VI), VI(VI), and extinction procedures as noted in Fig. 1 below. Rat No. 8 received $45 \mathrm{~min}$ of bar-press training in the first session and $10 \mathrm{~min}$ of subsequent training at the beginning of each of the next three sessions. Rat No. 8 developed middle ear infection in the midst of the experiment; its data are complete only through the FI(FI) procedure. Rats No. 33 and No. 34 received $60 \mathrm{~min}$ of bar-press training at the inception of the first session and $5 \mathrm{~min}$ at the beginning of the next three sessions. They were then introduced to FI(FI), VI(VI), and extinction. Rat No. 33 was observed to spend most of each session sitting on the bar. It never developed differences in responding in $S^{D}$ and $S^{\Delta}$, and its data are not presented.

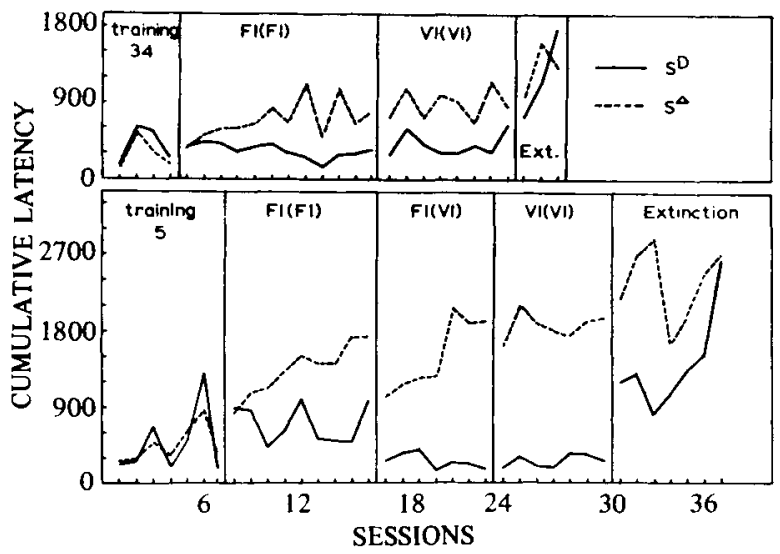

Fig. 1. Cumulative latency per session in $S \triangle$ and $S^{D}$ as a function of training sessions, with stimulus and shock schedules as indicated. 


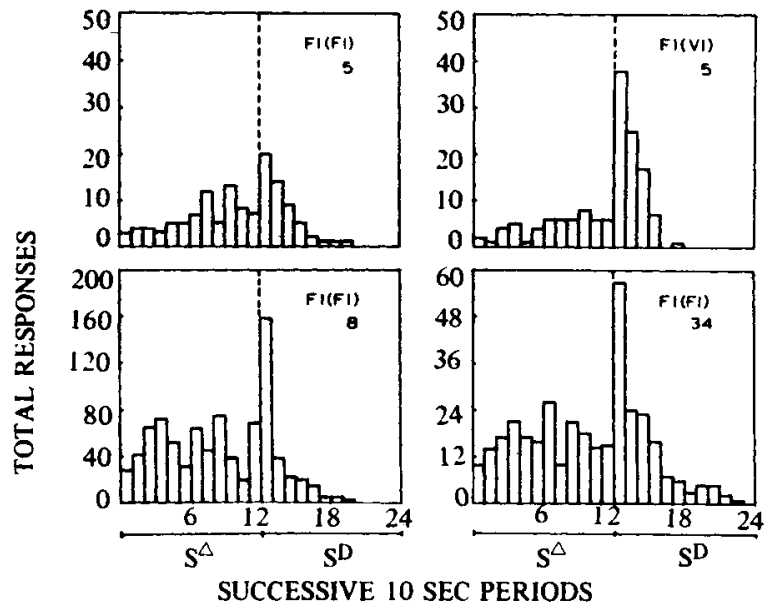

Fig. 2. Total responses per session in successive 10 sec periods of $S \triangle$, during which shocks were presented independently of response, and $\mathbf{S}^{D}$, in which the first response prevented the occurrence of all shocks for the remainder of the $S^{D}$ period. $S^{D}$ and $S \triangle$ alternated every $2 \mathrm{~min}$.

\section{RESULTS AND DISCUSSION}

The total latencies in $S^{D}$ and $S^{\Delta}$ (Fig. 1) of Rats No. 5 and No. 34 were indistinguishable in the initial stages of the training procedure, separated as exposure to the discrimination procedures continued, and then increased and came together during extinction. The data for Rat No. 8 exhibited a similar trend during the 15 sessions before its death. These results suggest that the avoidance contingency in $\mathrm{S}^{\mathrm{D}}$ was responsible for relatively short latencies in its presence; responding elicited only by shocks would presumably have had similar latencies in the presence of both stimuli.

The distribution of responding in the presence of $S^{D}$ and $S^{\Delta}$ during the final sessions of discrimination training with fixed stimulus periods is shown in Fig. 2. In all cases, responding was maximal during the first $10 \mathrm{sec}$ period following onset of $S^{D}$ with a decline in responding later in $S^{D}$. Rates of responding averaged throughout $\mathrm{S}^{\mathrm{D}}$ and $\mathrm{S}^{\Delta}$ periods did not differ consistently, but the distribution of responding is consistent with control by the contingency in $\mathrm{S}^{\mathrm{D}}$.

These results indicate that differential responding was established and maintained by an avoidance contingency correlated with an $S^{D}$. The procedure differed from the classical avoidance paradigm in that: (1) shocks were of inescapably short duration; (2) events were not scheduled in discrete trials; (3) the avoidance response did not terminate the external stimulus condition in the presence of which it was emitted: and (4) since fewer shocks were correlated with $S^{D}$ than with $S^{\Delta}$, it should have been a less fearful stimulus than $S^{\Delta}$ if it developed any fear characteristics at all. These results are therefore consistent with Herrnstein's (1968) interpretation of avoidance behavior in terms of contingent relations between stimuli, responses, and shocks.

Related research has been reported by Appel (1960) and Hake (1968). Portions of both studies involved a Sidman avoidance contingency (Sidman, 1953) during $\mathrm{S}^{\mathrm{D}}$, and noncontingent, unavoidable shocks during $S^{\Delta}$. Appel (1960) failed to obtain differential responding. Examination of his data shows that the actual frequencies of shock in $\mathrm{S}^{\mathrm{D}}$ and $\mathrm{S}^{\Delta}$ were approximately equal. In Hake's (1968) work, shocks were substantially less frequent in $\mathrm{S}^{\mathrm{D}}$, and differential responding was maintained. These studies suggest that obtained frequency of shock is an important determinant of discriminated avoidance performance. The present experiment extends these results by demonstrating that a continuous avoidance contingency during $S^{D}$ is not necessary to establish and maintain differential responding; a reduction in shock frequency appears to suffice.

\section{REFERENCES}

APPEL, J. B. The aversive control of an operant discrimination. Journal of the Experimental Analysis of Behavior, 1960, 3, 35-47.

HAKE, D. F. Actual versus potential shock in making shock situations function as negative reinforcers. Journal of the Experimental A nalysis of Behavior, 1968, 11, 385-403.

HERRNSTEIN, R. J. Method and theory in the study of avoidance. Unpublished manuscript, 1968

HERRNSTEIN, R. J., \& HINELINE, P. N. Negative reinforcement as shock frequency reduction. Journal of the Experimental Analysis of Behavior, 1966, 9, 421-430.

MOWRER, O. H., \& LAMOREAUX, R. R. Avoidance conditioning and signal duration-a study of secondary motivation and reward. Psychological Monographs: General and Applied, 1942, 54, 5. (Whole No. 247.)

SIDMAN, M. Two temporal parameters of the maintenance of avoidance behavior by the white rat. Journal of Comparative \& Physiological Psychology, 1953, 46, 253-261.

\section{NOTES}

1. Undergraduate research project under the direction of the junior author.

2. Presently at Columbia University. 